\title{
Neuroleptic Malignant Syndrome: Successful Treatment with Bromocriptine
}

\author{
Wim M. A. Verhoeven, Arthur Elderson, and \\ Herman G. M. Westenberg
}

\section{Introduction}

The neuroleptic malignant syndrome (NMS) is a potentially fatal complication of antipsychotic drugs and is characterized by severe muscle rigidity, hyperpyrexia, and autonomic dysfunctions (Delay and Deniker 1968). The pathogenesis of NMS is considered to be related to dopamine-receptor blockade in the basal ganglia and hypothalamus (Marsden and Jenner 1980; Henderson and Wooten 1981). Various therapeutic strategies have been employed, including conventional antiparkinsonian agents and dantrolene, but a specific treatment remains unclear (Caroff 1890; Smego and Durack 1982). Recently, a successful use of the dopamine-receptor agonist bromocriptine was reported in three cases with NMS (Granato et al. 1983; Mueller et al. 1983; Zubenko and Pope, 1983). This report describes a case in which bromocriptine was administered successfully to a patient with NMS induced by haloperidol. Some pathogenetic aspects of this syndrome are discussed.

From the Departments of Biological Psychiatry (W.M.A.V., H.G.M.W.) and Neurology (A.E.), University Hospital, Utrecht, The Netherlands.

Address reprint requests to Dr. W. M. A. Verhoeven, Department of Biological Psychiatry, University Hospital, Nicolaas Beetsstraat 24, 3511 HG Utrecht, The Netherlands.

Received July 13, 1984; revised December 7, 1984.

\section{Case Report}

A 17-year-old man, who had been healthy until September 1983, gradually developed a psychosis with paranoid symptoms. In the beginning of December he was treated with cis-clopenthixol orally (maximum daily dose $16 \mathrm{mg}$ ). Three days later, severe catatonic and dystonic symptoms occurred, which forced urgent hospitalization. After one injection with $40 \mathrm{mg}$ orfanedrine im, dystonic symptoms disappeared with $20 \mathrm{~min}$. However, the patient became progressively psychotic, with paranoid delusions and aggressive behavior, but had normal physical and neurological findings and normal hematological, blood biochemical, and urinary laboratory values. Upon treatment with high doses of benzodiazepines, anxiety and aggressive behavior became markedly reduced, but psychotic symptoms persisted. Subsequently, he received, within 1 week, two injections of $10 \mathrm{mg}$ haloperidol im, after which his psychotic state clearly improved, without the occurrence of any extrapyramidal side effects. It was then decided to treat him with haloperidol decanoate (total dose in 1 week, $150 \mathrm{mg}$ ) in combination with the anticholinergic drug dexetimide. Within 3 days after the second injection (100 $\mathrm{mg}$ haloperidol decanoate), severe extrapyramidal symptoms developed with mask-like facies, generalized muscle rigidity, impaired swallowing, hypersalivation, and obtundation. His sensorium, however, remained clear. The patient's tem- 
perature had risen to $39^{\circ} \mathrm{C}$, the serum creatine phosphokinase (CPK) rose to $1790 \mathrm{U} /$ liter (normal $<40 \mathrm{U} /$ liter), and serum transaminases slightly increased. Despite treatment with dexamethasone, benzodiazepines, and anticholinergics on an intensive care unit for 2 weeks, his clinical status did not change.

On February 2, 1984, he was transferred to the Department of Neurology of University Hospital under the preliminary diagnosis of NMS. On admission, the serum concentration of haloperidol was at the lower end of the therapeutic range $(1.4 \mu \mathrm{g} /$ liter; normal $1-20 \mu \mathrm{g} /$ liter $)$. No physical abnormalities were found. His body temperature was $38.5^{\circ} \mathrm{C}$. On neurological examination, generalized muscle rigidity with tremor of the hands, hypersalivation, and obtundation were observed. CT scan examination revealed no abnormalities. Serum transaminases were slightly increased and serum CPK markedly increased. The patient's homovanillic acid (HVA) level in cerebrospinal fluid (CSF), determined by means of high-pressure liquid chromatography in conjunction with electrochemical detection, was slightly decreased $(28 \mathrm{ng} / \mathrm{ml}$; normal $30-50 \mathrm{ng} / \mathrm{ml}$ ). In view of the lack of response to conventional medications and the lowered levels of HVA, it was decided to treat the patient with oral bromocriptine. On the sixth day of admission (Figure 1), bromocriptine was started in a dose of $1.25 \mathrm{mg}$ twice daily. On subsequent days, the dose was gradually increased to maximal, $20 \mathrm{mg} /$ day on day 13 . As can be inferred from Figure 1, a sharp decrease of plasma prolactin values $(<0.01 \mathrm{U} /$ liter $)$ occurred during treatment with bromocriptine, whereas serum CPK and body temperature returned to normal values within 1 week. By day 14 of bromocriptine treatment ( $5 \mathrm{mg} \mathrm{qd}$ ), muscle tone and tremor were markedly improved, the patient was alert and conversing; hypersalivation and profuse diaphoresis had disappeared. During the subsequent weeks of bromocriptine treatment, the level of HVA normalized (day $28,35 \mathrm{ng} / \mathrm{ml}$ ), as did liver function parameters. Only mild muscular rigidity remained. After discontinuation of bromocriptine (day 56), the clinical status of the patient remained un- changed. He was discharged 2 weeks later (day 71) with normal laboratory values (CPK, transaminases, HVA, prolactin), mental status, and neurological results, except for very mild muscular rigidity. Outpatient's control 4 weeks later revealed completely normal muscle tone.

\section{Discussion}

Our patient manifested various features typical of NMS, with extrapyramidal rigidity, autonomic dysfunction, and hyperthermia. The elevated serum transaminases and marked increase of serum CPK, which were present in our patient and have been noted in many cases of NMS, may be due to disturbances in liver function, although a relation to damage of other tissues cannot be excluded (Smego and Durack 1982). The marked decrease of plasma prolactin levels during treatment with bromocriptine is likely due to stimulation of dopaminergic receptors present in the pituitary and involved in prolactin secretion.

With respect to the pathogenesis of this disorder, several authors have compared NMS with malignant hyperthermia (MH), because both syndromes share the features of hyperpyrexia and muscular rigidity (Meltzer 1973). In MH, however, a genetically determined disturbance exists in the contraction of skeletal muscle (Britt 1974), whereas the pathogenesis of NMS is thought to be related to central dopaminergic blockade resulting in a dopaminergic hypoactivity. The latter is consistent with the fact that the neuroleptic potential for inducing NMS seems to parallel antidopaminergic potency and agrees with the observations that NMS can be caused by dopamine-depleting drugs (Burke et al. 1981) after discontinuation of a levodopa/carbidopa combination (Toru et al. 1981) or other antiparkinson drugs (Henderson and Wooten 1981).

Assuming that central dopaminergic hypoactivity is involved in the pathogenesis of MNS, the reported beneficial effects of treatment with carbidopa/levodopa combination or amantadine can easily be understood. The time course between the administration of the neuroleptics and the occurrence of the NMS suggests that factors 


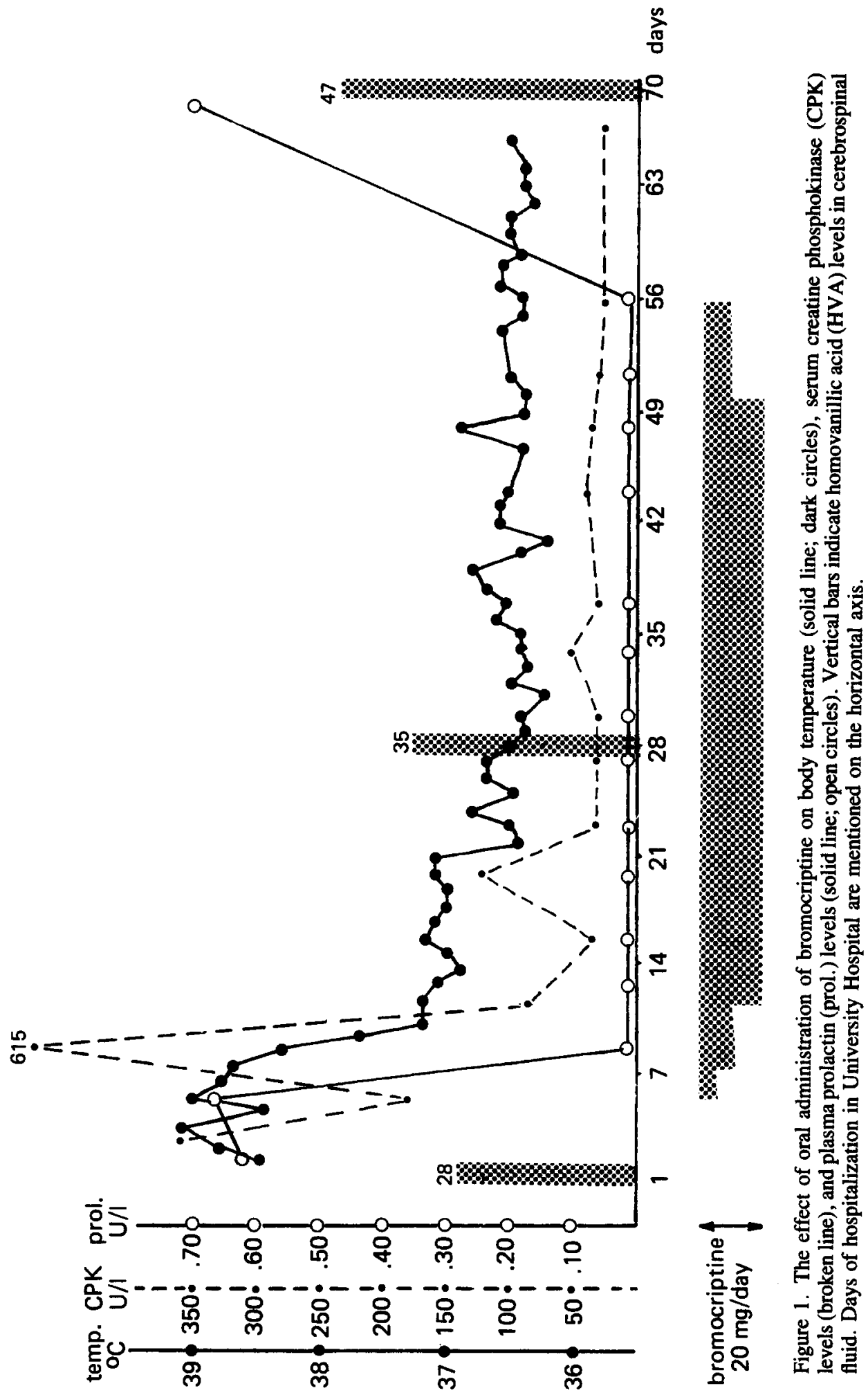


other than the acute effects of the neuroleptic are operative in the initiation of the syndrome. The physical state of the patient at the time of drug exposure may be a factor in determining the onset of NMS (Itoh et al. 1977). Furthermore, exposure to neuroleptics may initiate development of supersensitivity at both the presynaptically and postsynaptically located dopaminergic receptors. This supersensitivity at the presynaptic level may result in decreased dopamine output, and consequently, in lower HVA levels. The observed initially lowered HVA level in the CSF of the present patient supports this assumption, although Tollefson and Garvey (1984) have reported an increased level of HVA in the CSF of an NMS patient. Moreover, subnormal concentrations of HVA in CSF have also been reported in patients who developed extrapyramidal signs while receiving antipsychotic agents (Chase et al. 1970); and blood levels of HVA decrease during neuroleptic treatment (Pickar et al. 1984). It may be that the supersensitivity at the presynaptic level contributes to the marked dopaminergic hypoactivity, which is presumably present in patients with NMS. In our patient, HVA levels normalized in the course of treatment with bromocriptine, suggesting a normalization of the dopaminergic receptor system at the presynaptic site that parallels the reduction of muscle rigidity.

Whether or not the changes at presynaptically located dopaminergic receptor systems are pertinent to the symptoms of the NMS remains to be elucidated. The same holds for the site of action of bromocriptine with respect to its beneficial effect in NMS. This drug can stimulate postsynaptically located dopamine receptor systems, but evidence has been presented that bromocriptine can more potently activate certain dopaminergic receptors presumably present at the presynaptic level (Király and Van Ree 1984). Thus, at present, it is not clear whether dopaminergic receptors located presynaptically or postsynaptically, or both, are involved in the pathogenesis of NMS.

In conclusion, the described patient represents an underdiagnosed and potentially lethal side effect of treatment with certain neurolep- tics. The symptoms of the neuroleptic malignant syndrome disappeared after treatment with bromocriptine for several weeks. Although it is likely that this clinical improvement is due to bromocriptine treatment, a spontaneous remission cannot be excluded in view of the natural course of this syndrome. Nevertheless, the present and previous data favor bromocriptine for treatment of NMS. In case of severe hyperthermia, bromocriptine may be combined with dantrolene (Granato et al. 1983; Editorial 1984). However, administration of bromocriptine should be done carefully, as this drug might induce a new psychotic episode, and some patients may experience nausea and vomiting, increasing the risks of aspiration (Thorner et al. 1980).

The authors wish to express their thanks to W. Nelis, psychiatrist at the Lucas Hospital at Apeldoorn, for his willingness to comment on the manuscript critically

\section{References}

Britt BA (1974): Malignant hyperthermia: A pharmacogenetic disease of skeletal and cardiac muscle. $N$ Engl $J$ Med 1140-1142.

Burke RE, Fahn S, Mayeux R, et al (1981): Neuroleptic malignant syndrome caused by dopamine-depleting drugs in a patient with Huntington disease. Neurology 31:1022-1026.

Caroff SN (1980): The neuroleptic malignant syndrome. $J$ Clin Psychiatry 41:79-82.

Chase TN, Schnur JA, Gordon EK (1970): Cerebrospinal fluid monoamine catabolites in drug-induced extrapyramidal disorders. Neuropharmacology 9:265-268.

Delay J, Deniker P (1968): Drug-induced extrapyramidal syndromes. In Vinken PJ, Bruyn GW (eds), Handbook of Clinical Neurology: Diseases of the Basal Ganglia. New York: Elsevier-North Holland, pp 248-266.

Editorial (1984): Neuroleptic malignant syndrome. Lancet 1:545-546.

Granato JE, Stern BJ, Ringel A, et al. (1983): Neuroleptic malignant syndrome: Successful treatment with dantrolene and bromocriptine. Ann Neurol 14:89-90.

Henderson VW, Wooten GF (1981): Neuroleptic malignant syndrome: A pathogenetic role for dopamine receptor blockade? Neurology 31:132-135.

Itoh H, Ohtsuka N, Ogita K, et al (1977): Malignant neuroleptic syndrome-its present status in Japan and clinical problems. Folia Psychiatr Neurol Jpn 31:565-576.

Király I, Van Ree JM (1984): Non-opiate $\beta$-endorphin fragments and dopamine-VI: Behavioural analysis of the 
interaction between $\gamma$-type endorphines and dopaminergic systems in the nucleus accumbens of rats. $\mathrm{Neu}$ ropharmacology 23:511-516.

Marsden CD, Jenner P (1980): The pathophysiology of extrapyramidal side-effects of neuroleptic drugs. Psychol Med 10:55-72.

Meltzer HY (1973): Rigidity, hyperpyrexia and coma following fluphenazine nanthate. Psychopharmacologia 29:337-346.

Mueller PS, Vester JW, Fermaglich J (1983): Neuroleptic malignant syndrome: Successful treatment with bromocriptine. JAMA 249:386-388.

Pickar D, Labarca R, Linnoila M, et al (1984): Neurolepticinduced decrease in plasma homovanillic acid and antipsychotic activity in schizophrenic patients. Science 225:954-957.
Smego RA, Durack DT (1982): The neuroleptic malignant syndrome. Arch Int Med 142:1183-1185.

Thomer MO, Flückiger E, Calne DB (1980): Adverse reactions to bromocriptine. In Bromocriptine: A Clinical and Pharmacological Review. New York: Raven Press, pp 143-153.

Tollefson GD, Garvey MJ (1984): The neuroleptic syndrome and central dopamine metabolites. J Clin Psychopharmacol 4:150-153.

Toru M, Matsuda O, Makiguchi K, et al (1981): Neuroleptic malignant syndrome-like state following a withdrawal of antiparkinsonian drugs. $J$ Nerv Ment Dis 169:324-327.

Zubenko G, Pope HG (1983): Management of a case of neuroleptic malignant syndrome with bromocriptine. Am J Psychiatry 140:1619-1620.

\section{Platelet Monoamine Oxidase Inhibition by Deprenyl and Tranylcypromine: Implications for Clinical Use}

\section{George M. Simpson, Eric Frederickson, Ruby Palmer, Edmond Pi, R. Bruce Sloane, and Kerrin White}

\section{Introduction}

The upsurge of research with monoamine oxidase inhibitors (MAOIs) has raised two methodological issues with important clinical and theoretical implications: the adequacy of dosage and the usefulness of platelet monoamine oxidase (MAO) inhibition as an index of adequate

\footnotetext{
From the Medical College of Pennsylvania at Eastern Pennsylvania Psychiatric Institute (G.M.S., E.P.), Philadelphia, PA; the University of Southern California School of Medicine, Department of Psychiatry and the Behavioral Sciences (E.F., R.P., R.B.S.) Los Angeles, CA; and McLean Hospital (K.W.), Belmont, MA. Address reprint requests to Dr. George M. Simpson, Eastern Pennsylvania Psychiatric Institute, 3200 Henry Avenue, Philadelphia, PA 19129.

Received April 19, 1984; revised December 20, 1984.
}

treatment. For example, the work of Robinson et al. (1978) and Georgotas et al. (1983) with phenelzine has suggested that antidepressant effects occur with dosages of about $1 \mathrm{mg} / \mathrm{kg} /$ day, or platelet MAO inhibition of $>80 \%$, and that the time course of enzyme inhibition parallels that of clinical improvement.

However, MAOIs have other effects besides enzyme inhibition, and it is far from clear that this is the mechanism of overriding therapeutic importance (Hendley and Snyder 1968; Karoum et al. 1982). Even if it were, the key variable would presumably be brain MAO activity, and the use of platelet MAO as a model would still pose problems. For example, platelet MAO is almost exclusively of the B type, which is pref- 